\section{DESPOSESIÓN Y PRODUCCIÓN DE IRREGULARIDAD: LA GESTIÓN DE LAS MIGRACIONES EN LA ERA DEL NEOLIBERALISMO}

\author{
Noelia González Cámara \\ Instituto de Filosofía - CCHS (CSIC), Madrid
}

\section{DISPOSSESSION AND PRODUCTION OF ILLEGALITY: MANAGING MIGRATIONS IN THE AGE OF NEOLIBERALISM}

\begin{abstract}
Approaching the discussion on the production of migrant illegality, this paper analyzes the Spanish case focusing the attention on the consequences of the relations between the logics of political power and economic power in the categorization of undocumented migrants. The first part of the paper briefly reviews the latest and most outstanding contributions to the critical study of illegality, examining which dimensions participate in the process of illegalization according to these proposals. In the second part I suggets that in the age of neoliberalism the production of migrant illegality can be understood as a process of accumulation by dispossession attending to the relation established between the State and capital. Finally, the process of illegalization that has taken place in Spain in the last decades is explored.
\end{abstract}

KEY WORDS: Undocumented migration; production of migrant illegality; Spain; accumulation by dispossession; David Harvey.

Los migrantes irregulares son representados habitualmente como una figura paradigmática de la privación y la negación. Su condición ha sido descrita con frecuencia a partir de la ausencia de derechos y de agencia política, destacando la invisibilidad y la precariedad de su status. El énfasis en las múltiples formas de desposesión que padecen los inmigrantes ha generado que las investigaciones teóricas se hayan concentrado fundamentalmente en el estudio de las formas de exclusión que experimentan, con el coste de dejar a un lado la pregunta acerca de los orígenes de tal situación. Así, desde la filosofía en contadas ocasiones se ha prestado atención al hecho de que la posición del migrante irregular no es fortuita ni casual, sino que es producida de manera activa'. Es éste precisamente el objeto del que se ocupa esta investigación.

La propuesta del presente artículo consiste en realizar una aproximación al debate sobre los procesos que inter-
RESUMEN: Retomando el debate sobre los procesos que participan en la categorización, diferenciación y producción de migrantes irregulares, este trabajo propone realizar un análisis de los factores que han intervenido en las últimas décadas en la producción de irregularidad en el contexto español. En el primer apartado se revisan de forma somera algunas de las aportaciones más relevantes que se han realizado en el estudio crítico de la producción de irregularidad en los últimos años, prestando atención a las dimensiones que según las distintas interpretaciones participan en este proceso. En el segundo apartado se plantea que la producción de irregularidad en la era del neoliberalismo cabe ser interpretada, de la mano de David Harvey, como un proceso de acumulación por desposesión debido a la forma que en él se conjugan las dinámicas del Estado y del capital. Por último, se atiende a la forma en la que se ha concretado el proceso de irregularización en el caso español en las últimas décadas.

PALABRAS CLAVE: Migración irregular; producción de irregularidad migratoria; España; acumulación por desposesión; David Harvey.

vienen en la producción de irregularidad migratoria -desarrollado hasta el momento fundamentalmente desde la antropología y la sociología de las migraciones, la historia y el derecho- analizando cómo se han combinado en el caso español las relaciones entre las lógicas contrapuestas del poder político y del poder económico. Para ello en el primer apartado se revisarán de forma somera algunas de las aportaciones más relevantes que se han realizado en el estudio crítico de la producción de irregularidad en los últimos años, prestando atención a los agentes que participan en este proceso según las distintas interpretaciones. En el segundo apartado se plantea que la producción de irregularidad en la era del neoliberalismo puede ser concebida, de la mano de David Harvey, como un proceso de acumulación por desposesión por la forma en la que en él se conjugan las dinámicas del Estado y el capital. Por último, se atenderá a la forma en la que se 
ha concretado el proceso de irregularización en el caso español en las últimas décadas.

\section{Aproximaciones CRíticas aL ESTUdIO DE LAS MIGRACIONES IRREGULARES}

Una línea de trabajo cada vez más extendida en el estudio de las migraciones irregulares incide en la necesidad de cuestionar el tratamiento de la migración irregular como un hecho dado, como una realidad independiente y ajena del Estado receptor (entre otros: Calavita, 1998, 2005; Coutin, 2000; Dauvergne, 2008; De Genova, 2002; Garcés Mascareñas, 2010; Goldring et al., 2007; Izquierdo, 1996; Jabardo, 1995; Ngai, 2004; Solanes Corella, 2003). Desde esta perspectiva se subraya la relevancia de los procesos mediante los que ciertas formas de entrada o residencia son catalogadas y categorizadas como irregulares. Partiendo de distintos puntos de vista y haciendo hincapié en diferentes elementos, las investigaciones realizadas hasta el momento han sostenido que la condición del migrante irregular es producida a través de las relaciones de orden legal, político, económico o social que se establecen en el Estado de acogida entre el migrante, la administración, los ciudadanos y el mercado de trabajo. Frente al estudio de la experiencia aislada del migrante irregular, en estos trabajos cobra importancia analizar el papel de las instituciones a la hora de determinar si la entrada o la residencia no autorizada tienen asociadas un status legal propio y si traen parejo un mayor o menor cuerpo de derechos; si la irregularidad migratoria supone la prohibición de desempeñar actividades laborales y, por tanto, una posición subordinada en el mercado de trabajo; si puede acarrear la posibilidad de la expulsión; y, asimismo, si la irregularidad migratoria implica la reducción de la capacidad de agencia política de los recién llegados.

El rasgo común a los estudios que abordan de forma crítica la irregularidad no es, por tanto, plantear por qué se producen las migraciones, o más concretamente, por qué tienen lugar las migraciones no autorizadas en tanto que desplazamientos internacionales de población, sino cómo se atribuye a determinados movimientos y sujetos el significado "irregular" y qué consecuencias tiene para quienes lo experimentan (esta cuestión ha sido planteada de forma amplia en relación con las prácticas ilícitas e ilegales por
Abraham y Van Schendel, 2010). La irregularidad, como condición del migrante irregular, se constituye, así en el objeto de estudio, sustituyendo a la figura del migrante irregular (De Genova, 2002).

Las investigaciones que abordan el estudio de las migraciones irregulares desde una perspectiva crítica y que introducen el análisis del papel de la ley, de las políticas migratorias o de la economía capitalista en el proceso de irregularización han cobrado fuerza en la última década, aunque los primeros pasos se remontan al menos a mediados de la década de los años setenta. La conceptualización y teorización de la irregularidad migratoria, sin embargo, no se ha abordado en todos los casos desde el mismo marco y con los mismos presupuestos. Un núcleo importante de trabajos se ha realizado tomando en consideración el papel de la ley como instrumento a merced de instancias superiores: bien en manos de la lógica de la economía capitalista (Bach, 1978; Brandariz Garcia, 2009; Burawoy, 1976), o bien como una esfera que opera de la mano del Estado para el reforzamiento de su soberanía y su legitimidad (Nevins, 2002). Se ha constituido, además, una tercera línea de trabajo que destaca el papel de la ley como agente productor de irregularidad, pero en este caso sin vincular su actuación a ningún factor exterior (Dauvergne, 2008; Garcés Mascareñas, 2010; Ngai, 2004). Por último, en algunos trabajos se ha señalado de forma puntual la necesidad de identificar las relaciones dinámicas que tienen lugar entre la esfera legal y la política en la producción de irregularidad (Clandestino Research Project, 2009: 3; Düvell, 2010: 302) y de forma más desarrollada se ha planteado el estudio de las relaciones dinámicas entre la lógica limitada del Estado y la lógica expansiva capitalista (Calavita, 2005; De Genova, 2002).

Desde una perspectiva cronológica, las primeras investigaciones que han planteado cuáles son los procesos que intervienen en la producción de migración irregular datan de la década de los años setenta. A partir del análisis de la migración mexicana en Estados Unidos Burawoy concluyó que el trabajo migrante no es algo que esté dado de forma natural sino que es creado y recreado por el Estado, pues está en su mano establecer si el migrante será tratado bajo las mismas condiciones que el trabajador nativo (Burawoy, 1976: 1076). Y en esta misma línea Bach señaló pocos años después que las intervenciones políticas y legales del Estado norteamericano en la frontera con México fueron 
las que dieron lugar a la creación de migración irregular (Bach, 1978: 548). No obstante, en ambos trabajos el papel que se atribuye al marco legislativo en la gestión de las migraciones es derivado de una racionalidad superior ${ }^{2}$. La producción de irregularidad a través de la ley se plantea como un efecto exclusivo de la dinámica del mercado y aquélla es tratada como un instrumento al servicio del capital. Este acercamiento plantea limitaciones teóricas importantes, pues se impide conectar la gestión de las migraciones con los procesos de construcción nacional, con el contexto geopolítico en el que un Estado aprueba una determinada normativa, la herencia de políticas coloniales e imperialistas, etc.

Otras aproximaciones a los contextos en los que tiene lugar la irregularización de migraciones han señalado que este proceso posee un carácter multidimensional, salvando de esta manera los obstáculos identificados en el enfoque anterior. La irregularidad migratoria se ha interpretado como resultado de la combinación de procesos en los que intervienen los intereses de los contratistas particulares, las tendencias globales de flexibilización del mercado de trabajo, así como las políticas de inmigración estatales aprobadas en el marco de integración regional supranacional. Las investigaciones de Jabardo, Izquierdo y Calavita que han abordado de forma crítica el estudio de las migraciones irregulares en España en la década de los años noventa se encontrarían en este segundo grupo. En estos casos la producción de irregularidad se plantea como un efecto del marco legislativo e institucional, sin considerarlo un elemento auxiliar de la lógica de acumulación capitalista, aunque eventualmente se pueda combinar con él. El estudio de Jabardo sobre el papel de la mano de obra extranjera en las explotaciones agrícolas catalanas identifica que en el caso español la ley de extranjería 7/1985 fue la autora de la categoría del migrante "ilegal" (Jabardo, 1995: 87). Pero, además, apunta que en la diferenciación del status del migrante regular e irregular intervinieron los procesos de modernización y transformación del sector de la agricultura mediante los cuales los migrantes irregulares se configuraron como mano de obra barata y precaria.

Por su parte, las investigaciones realizadas por Antonio lzquierdo han contribuido al estudio crítico de la irregularidad al plantear que la migración irregular responde a un proceso de diferenciación resultado de la actuación de distintas instituciones (Izquierdo, 1996). Este autor destaca que la pro- ducción de migrantes irregulares se debió a factores como a la puesta en marcha de un proceso de regularización tras la aprobación de la ley de extranjería de 1985 que denegó un porcentaje considerable de solicitudes en el procedimiento inicial, así como en la fase de renovación posterior, de manera que dos años después de la regularización sólo el 64\% de los migrantes mantenía el status regular. Siguiendo los pasos de estas investigaciones, los trabajos realizados por Suárez Navaz y Calavita (Calavita, 1998, 2005; Calavita y Suárez Navaz, 2003) hacen hincapié en que la situación de los migrantes irregulares en España es fruto de un proceso continuo de irregularización que se ha implementado a través de las legislaciones puestas en marcha desde los distintos niveles de la Administración española. Además apuntan que a nivel social la producción de irregularidad ha consistido en la desactivación de las alianzas entre nacionales y trabajadores extranjeros de países extracomunitarios y en la puesta en marcha de procesos de identificación social que toman como eje la ciudadanía nacional o incluso la europea (Calavita y Suárez-Navaz, 2003: 121). En el debate académico se ha señalado que el mérito de las conclusiones de esta investigación es doble, por un lado, destaca su capacidad para conceptualizar y teorizar la irregularidad migratoria y, por otro, también consiste en haber abierto un ámbito específico de estudio que indaga específicamente en el contexto de producción de la irregularidad (Goldring et al. 2007: 5), trabajo que se ha consolidado con las aportaciones de Coutin (2000) y De Genova (2002).

Más allá del contexto español, en la última década se han multiplicado los estudios que se han interesado por analizar los factores que intervienen en la diferenciación de la migración irregular de la regular (entre otros: Clandestino Research Project, 2009; Goldring et al., 2007; Nevins, 2002). Las investigaciones de Susan Coutin se han centrado en el estudio de los migrantes salvadoreños en Estados Unidos planteando cómo la ley oficial de inmigración ha relegado a estos migrantes a una inexistencia legal que es producida a través de la exclusión, la limitación de derechos, la restricción en el acceso a servicios y el desmantelamiento de la personalidad legal (Coutin, 2000: 28). Esta investigación apunta que la irregularidad es producida a través de la legislación, de manera que "a pesar de que pueda parecer que la ley de inmigración estadounidense exista en parte para combatir la inmigración ilegal, también es verdad que los migrantes irregulares se producen a través de las leyes que criminalizan su presencia" (Coutin, 2000: 55). 
Otro trabajo que ha tenido una repercusión notable en la academia ha sido realizado por Nicholas de Genova, quien defiende la necesidad de visibilizar el papel de la ley en la producción de irregularidad migratoria y de poner en tela de juicio el tratamiento de la irregularidad como una realidad "transhistórica" (De Genova, 2002: 431). La génesis y la evolución de la representación de la migración mexicana en Estados Unidos como "ilegal" es analizada a partir del tratamiento que se le ha otorgado desde el ámbito legislativo, pero prestando también atención a las relaciones que tienen lugar entre la economía global capitalista y la movilidad de la fuerza de trabajo. De esta manera quedan vinculadas en su planteamiento la producción legal y la producción económica de irregularidad migratoria.

La relevancia del marco legislativo en la producción de la migración irregular también ha sido objeto de análisis en los trabajos de la historiadora Mae Ngai (2004) y en el campo del derecho en las investigaciones realizadas por Dauvergne (2008) y Solanes (2003). Otra contribución reciente ha sido realizada desde el ámbito de la sociología por Garcés Mascareñas (2010) en un estudio comparado entre los casos de España y Malasia. En este trabajo la autora plantea que el hecho de que la fuerza de trabajo migrante haya adquirido los atributos de ser flexible y barata no es más que una consecuencia de su posición legal. Deja así relegada a un segundo plano la dimensión económica de la irregularidad como aspecto empírico derivado y plantea que carece de validez como "punto de partida para la investigación" (2010: 79).

La revisión de las distintas aproximaciones que se han realizado a la producción de irregularidad pone de manifiesto que existe una gran divergencia en la interpretación de los factores que participan en dicho proceso. Una explicación puede ser que los análisis remiten a Estados y a momentos históricos distintos y no tienen por qué coincidir en sus diagnósticos. Sin embargo, también se puede vincular esta divergencia de pareceres a la notable distancia que existe entre los marcos conceptuales desde los cuales se han realizado las investigaciones, aspecto que se advierte en el afán de estos trabajos por jerarquizar de forma concluyente la dimensión legal y la dimensión económica en el proceso de irregularización. Así por ejemplo, mientras Brandariz García (2009: 3) plantea que las políticas migratorias en el sistema español son subsidiarias de los requisitos del mercado de trabajo postfordista para la obtención de trabajadores sobreexplotables y precarios, el trabajo de Garcés Mascareñas invierten esta secuencia y plantea que la irregularidad migratoria se puede explicar atendiendo exclusivamente a las disposiciones legales, siendo la explotación del trabajo migrante un efecto empírico (Garcés Mascareñas, 2010: 79) $y_{1}$ en este sentido, se podría interpretar como un aspecto coyuntural. Partiendo del análisis de los procesos de irregularización de migraciones de países extracomunitarios en España, pero distanciándome de los esfuerzos por reducir a un único factor la producción de irregularidad, la propuesta que formularé en las siguientes páginas consiste en situar en un mismo plano la dimensión legal, política y económica en la configuración de esta condición ${ }^{3}$. En este sentido, propondré una interpretación de sus interacciones como fruto de una relación dialéctica entre los polos de la lógica limitante y excluyente del poder del Estado (como intersección de la dimensión legal y política) y la lógica expansiva e ilimitada del poder económico capitalista.

La hipótesis que planteo implica, por un lado, que un marco legal que sancione las formas de entrada y residencia no autorizadas no es suficiente para hacer efectiva la diferenciación y categorización de los migrantes sin autorización como irregulares. La codificación de estas actividades como faltas administrativas o como delitos ha de venir acompañada de la implementación de políticas que hagan efectiva la ley y que creen una distancia significativa entre el status del migrante regular y el irregular ${ }^{4}$. La dimensión política además es relevante a la hora de establecer si los criterios de acceso al territorio serán exigidos a toda la población extranjera o sólo a la población de cierta procedencia, concentrando la irregularidad de esta manera sobre los nacionales de determinados Estados. En el ámbito de la Unión Europea el hecho de que se haya establecido el régimen comunitario y que se hayan firmado acuerdos de supresión de visados con buena parte de los países desarrollados ha dado lugar a que la irregularidad se haya convertido de facto en una condición propia de los migrantes que proceden de países del Sur (López Sala, 2003: 162-163). Por otro lado, también queda en manos del poder político definir la intensidad con la que se realizarán controles de identidad y cuál será el esfuerzo invertido en llevar a cabo la expulsión de los migrantes irregulares. En este sentido, se puede afirmar que la irregularidad es producida políticamente, y no sólo legalmente (Abraham y Van Schendel, 2005: 19; Clandestino Research Project, 2009: 3; Düvell, 2010: 302). 
No obstante, la vulnerabilidad que caracteriza a la condición del migrante irregular en el caso de España no se debe únicamente a su status legal y al efecto de las políticas en materia de inmigración. También tiene un papel protagonista en la definición de su condición el nuevo régimen de acumulación flexible de capital que busca incorporar mano de trabajo precaria al mercado de trabajo. En este sentido, su posición es inferiorizada y subordinada también desde el ámbito laboral, algo que no se puede explicar como una mera consecuencia de su débil status legal pues se trata de tendencias que también afectan a los trabajadores nacionales y cuyas consecuencias afectan a muchos aspectos de la organización de la producción. En este nuevo escenario de transformación del mercado de trabajo debido a las corrientes de desregulación, terciarización y desindustrialización, a procesos de debilitamiento de la capacidad de negociación colectiva y a la demanda de un nuevo perfil de trabajador dispuesto a asumir condiciones de trabajo flexibles (Schierup et al., 2006: 106, Izquierdo 1996a: 196; King, 2001: 10; López Sala, 2003: 89, Romero, 2010: 82), el migrante es incorporado en el sector económico como un factor del que se puede prescindir en las fases del proceso productivo que no sea necesario. El hecho de que disponga de un status legal débil facilita que sea diferenciado del resto de trabajadores y que se constituya como un suministro de mano de obra dispuesto a asumir condiciones que no aceptaría un trabajador nacional, pero en cualquier caso es necesario tener en cuenta que el origen de estas tendencias que buscan configurar este tipo específico de fuerza de trabajo no se encuentra en el ámbito legal, sino en el económico. Así, parece más oportuno plantear que son las interacciones entre el ámbito legal y el ámbito económico las que definen la posición del migrante en la sociedad de acogida, y no cualquiera de estos dos ámbitos por separado.

En definitiva, en esta propuesta se plantea que en la producción de irregularidad migratoria actúa por un lado la ley y las políticas de inmigración definiendo qué casos son considerados residencias y entradas no autorizadas, estableciendo a los nacionales de qué Estados afecta y determinando las consecuencias legales de esta situación y, por otro lado, pero ahondando en la diferenciación del migrante irregular, actúa el papel que se reserva en el nuevo régimen de acumulación flexible al trabajo precario y que, junto a otros sectores de la población, desempeñan los trabajadores migrantes en situación administrativa irregular. En este sentido, sostengo que esta producción económica de irregularidad no es una mera consecuencia de la exclusión legal, sino que ambas se constituyen mutuamente (Calavita, 2005: 72; Solanes Corella, 2003: 131 y 136).

Para examinar cómo se han combinado en la era del neoliberalismo la actuación del Estado en la gestión de las migraciones con las prácticas de la economía capitalista se propone tomar en consideración a continuación el trabajo del geógrafo David Harvey sobre la acumulación por desposesión. Su obra permite analizar con profundidad la forma en la que se entrelazan las lógicas en principio opuestas del poder político y del poder económico y ofrece herramientas con las que identificar la particular combinación de estas dos dimensiones en la producción de irregularidad migratoria.

\section{ACUMULACIÓN POR DESPOSESIÓN, NEOLIBERALISMO $Y$ TRABAJADORES DESECHABLES}

La noción de acumulación por desposesión ha sido formulada por David Harvey para dar cuenta del carácter duradero y persistente de las formas de acumulación no basadas en la producción. Según este autor, la depredación, la desposesión y la colonización de ámbitos que previamente no estaban mercantilizados continúa siendo una práctica habitual de acumulación más allá del inicio del modo de producción capitalista. Su tesis, sin embargo, ha resultado controvertida (Ashman y Callinicos, 2006: 125; Dunn, 2007: 23; Glassman, 2006, 2009; Hartsock, 2006) por sostener que a partir de los años setenta la acumulación por desposesión, de la mano de las políticas neoliberales, ha desplazado a la reproducción ampliada como principal mecanismo de acumulación (Harvey, 2007a: 142) Esta propuesta se enmarca en un debate que es un viejo conocido entre las filas del materialismo histórico (entre otros: Amin, 1974; Luxemburg, 1951; Wolpe, 1972) en el que se discute si las prácticas de acumulación primitiva que produjeron la separación de los trabajadores de los medios de producción y que dieron lugar a la proletarización de la fuerza de trabajo sólo tienen carácter histórico, y por tanto están relegadas a los orígenes del modo de producción capitalista (posición defendida recientemente por Zarembka, 2002), o si se trata de prácticas continuas 
y contemporáneas que son empleadas para reanimar los procesos de acumulación (entre sus valedores actuales se encuentran Ashman y Callinicos, 2006; Auerbach y Negi, 2009; Bonefeld, 2001; Brenner, 2006; Dalla Costa, 2004; De Angelis, 2001, 2004; Glassman, 2006; Hart, 2006; Hartsock, 2006; Midnight Notes Collective, 2001; Perelman, 2000; Retort, 2005; Vasudevan et al., 2008). La propuesta de Harvey se encontraría dentro de la segunda línea de argumentación.

El rasgo definitorio de los procesos de acumulación por desposesión, según el geógrafo, es que a través del uso de estrategias económicas o extra-económicas se pone a disposición del capital un ámbito que previamente no estaba abierto a la explotación capitalista para que sea sometido a procesos de mercantilización, privatización o proletarización. En palabras de Harvey: "la acumulación por desposesión lo que posibilita es la liberación de un conjunto de activos (incluida la fuerza de trabajo) a un coste muy bajo (y en algunos casos nulo). El capital sobreacumulado puede apoderarse de tales activos y llevarlos inmediatamente a un uso rentable" ${ }^{5}$ (Harvey, 2007a: 119). Se trata de un tipo de acumulación cuyo efecto es la producción ex novo de la separación del trabajador de sus medios de producción (De Angelis, 2001). Este tipo de acumulación cuenta con cuatro aspectos fundamentales: a) la privatización de bienes públicos y la mercantilización de recursos naturales, culturales y sociales, b) la financiarización, por ejemplo, mediante la manipulación de acciones, c) la gestión y manipulación de las crisis, d) y las redistribuciones estatales, en forma de recortes de gasto público o de reformas tributarias que favorecen las inversiones frente a los salarios (Harvey, 2007b: 175 y ss.). Las prácticas en las que ha cristalizado la acumulación por desposesión son dispares y abarcan desde el desplazamiento de población campesina en India o México, hasta los acuerdos mediante los cuales las patentes y licencias blindan a determinadas poblaciones el acceso a productos a cuya elaboración han contribuido, pasando por la privatización de instituciones públicas, viviendas sociales, telecomunicaciones, transportes, agua, sanidad, educación, etc. (Harvey, 2007a: 114 y ss.; ver otras aplicaciones en Brüscher, 2009; Mahmud, 2010; Proudham, 2007).

A juicio de Harvey, el principal agente de la ola de procesos de acumulación por desposesión son las fuer- zas económicas, concretamente el poder financiero y el sistema de crédito (Harvey, 2006: 159, 2007a: 123; Proudham, 2007: 413), y no las fuerzas extra-económicas (Glassman, 2006). No obstante, precisa que los procesos de acumulación por desposesión necesitan el apoyo de las instituciones del Estado para lograr alcanzar sus objetivos. Al igual que en los procesos de acumulación primitiva que describe Marx en El Capital, el poder del Estado no es imparcial ni permanece al margen de los dispositivos contemporáneos de desposesión (Marx 2009: cap. XXIV). El papel del Estado fue esencial para iniciar el proceso de acumulación capitalista en Inglaterra, pues permitió la concentración de las propiedades inmobiliarias y el capital en unas pocas manos a través de la legitimación de los cercamientos de bienes comunales, llevó a cabo la expropiación del productor directo y sometió mediante las nuevas legislaciones de vagabundaje y de trabajo a los asalariados libres a las condiciones que imponía el capital (Marx, 2009: 895-929). En la actualidad, la privatización de recursos naturales o la empresarización de servicios públicos, por ejemplo, son prácticas que requieren de forma inevitable la actuación del Estado a favor de la promoción de estos procesos de acumulación, señala Harvey. En el caso de la puesta en marcha de las políticas neoliberales desde finales de los años setenta sostiene que se ha producido una transformación radical de la forma de aplicación del poder del Estado para poder implantar una forma de comercio más libre (Harvey, 2007a: 124). No obstante, la participación del Estado en estos procesos no es síntoma de que actúe a expensas del capital.

Para Harvey la lógica del poder estatal no es subsidiaria del poder económico ni actúa por definición bajo las órdenes de éste. El Estado posee una dinámica propia que en determinadas fases puede coincidir con la dinámica económica y dar lugar a un funcionamiento acompasado de la lógica territorial del poder y la lógica capitalista del poder, adquiriendo sus relaciones formas complejas y contradictorias. Asumiendo el planteamiento de Arendt sobre el papel del Estado en el imperialismo de ultramar (2006: 227), Harvey sostiene que la dinámica del Estado consiste en el mantenimiento del poder en un territorio determinado y, para ello, en ocasiones resulta conveniente intervenir mediante sus instituciones en los procesos moleculares de acumulación y favorecer aquellos intereses que actúan en su marco y que refuerzan su poder 
como institución política (Harvey, 2007a: 109). Así, el Estado tiene el papel de ser un agente mediador en los procesos de acumulación que puede consistir en actuar a través de la imposición de límites a la acumulación o en intervenir como un agente activo que favorece dicho proceso, en función de qué opción permita fortalecer el poder político que ostenta. Se puede tomar como ejemplo los nuevos cercamientos de bienes comunales que se configuran bajo la forma de privatizaciones de servicios y bienes públicos pues, aunque se llevan a cabo utilizando el poder del Estado en contra de la voluntad popular, tratan de ordenar el proceso de acumulación dentro de sus estructuras de manera que beneficien a los intereses capitalistas que operan en su marco (Harvey, 2007a: 109 y 118). En estas páginas propongo tomar en consideración el caso de la producción de irregularidad migratoria, donde también se produce una simbiosis entre las dinámicas en principio opuestas del poder político y económico. Mientras el Estado actúa a través de la imposición de criterios de acceso y residencia restrictivos que tienen como objetivo definir los límites que se da a sí misma la sociedad receptora, la dinámica ilimitada de la economía capitalista tiende a la búsqueda de recursos, que en el caso del nuevo régimen de acumulación flexible pasa por buscar yacimientos de mano de obra barata y, sobre todo, fácilmente desechable. La producción de irregularidad se puede interpretar como un resultado de la interacción entre estos dos impulsos antagónicos y mediante la cual se crea una nueva mercancía: el trabajador superfluo o desechable.

Para desarrollar esta hipótesis hay que tomar en consideración que en planteamiento de Harvey el predominio de las prácticas de acumulación basadas en la desposesión en la era del neoliberalismo ha tenido efectos en las relaciones laborales, concretamente en la potenciación de la flexibilización del mercado de trabajo y de los contratos de corta duración. La extensión de la inseguridad laboral crónica, la pérdida de protecciones sociales, así como la destrucción de instituciones colectivas ha permitido modelar la fuerza de trabajo al servicio de las necesidades del mercado (Harvey, 2007b: 187). En este contexto de flexibilización, que busca reducir la contratación de mano de obra sólo a aquellas fases del proceso productivo que sea imprescindible, el "trabajador desechable" se constituye en el prototipo del trabajador requerido por la neoliberalización.
La figura de este "trabajador desechable" que presenta Harvey es amplia e intenta dar cuenta de las condiciones de explotación a las que son sometidos los trabajadores migrantes irregulares, los trabajadores migrantes temporeros, las mujeres empleadas en las maquilas o los regímenes de trabajo semi-esclavo de la población rural que ha emigrado sin autorización a zonas urbanas en China (Harvey, 2007b: 185 y ss.). Dado que Harvey hasta el momento sólo ha bosquejado los vínculos entre el "trabajador desechable" y las formas de acumulación por desposesión en el neoliberalismo, la propuesta que formulo en este artículo consiste en tematizar de forma específica la relación entre los mecanismos de acumulación por desposesión y la producción de irregularidad migratoria durante los últimos años.

Para desgranar las características que permiten interpretar la producción de irregularidad como un mecanismo de acumulación por desposesión es preciso dar cuenta de la forma en la que cristaliza la relación dialéctica entre el poder político y el poder económico en esta ocasión. Desde mi punto de vista, en este proceso la actuación del Estado no se limita a dotar de contenido a la irregularidad a través de la negación de protecciones legales a los migrantes no autorizados, también define esta condición a través de la gestión de la amenaza de expulsión, también denominada "deportabilidad" (De Genova, 2002). Mediante la gestión de este dispositivo se obtiene una reducción casi total de la capacidad de acción política del migrante (independientemente de que exista un reconocimiento formal de derechos políticos). El hecho de que la mera presencia del migrante no autorizado sea calificada por las instituciones como una presencia irregular y que esto faculte al Estado para expulsarlo de su territorio convierte la amenaza de la expulsión en un potente mecanismo de sujeción de los migrantes no autorizados. Visibilizar su situación, realizar apariciones en el ámbito público y llevar a cabo acciones políticas con el objetivo de reivindicar una mejora en sus condiciones de vida, una revisión del tratamiento que le brindan las instituciones del Estado o una mejora de las condiciones laborales supone un riesgo difícilmente asumible en la mayor parte de las ocasiones.

Asimismo, hay que tomar en consideración que la amenaza de expulsión es gestionada por el poder político, implementándola o no, con la mirada puesta en reforzar su posición ante distintos agentes sociales. De esta manera 
en un determinado momento puede decidir favorecer las demandas nacionalistas de los ciudadanos, las reivindicaciones de proteccionismo de la mano de obra nacional o puede ofrecer una imagen pública de control de los flujos migratorios a través de identificaciones discriminatorias basadas en aspectos raciales y expulsiones de migrantes irregulares. La gestión de la amenaza de la expulsión sirve también como instrumento con el que disciplinar al migrante irregular ante posibles recortes en el acceso a derechos que previamente le eran reconocidos o ante las protestas que puede generar la denegación de la concesión de status regular. En sentido contrario, la capacidad de gestionar las expulsiones también se puede modular suspendiendo deliberadamente su ejercicio con el objetivo de acallar las críticas de sectores de la sociedad que reclaman un tratamiento de los migrantes respetuoso con los derechos humanos o con la intención de atender a las presiones que ejerzan los empresarios que en determinados momentos requieren su fuerza de trabajo. En todos estos casos la intervención de las instituciones del Estado no se explica porque actúe a expensas de la lógica del capital, sino porque trata de conciliar sus objetivos con los de diferentes sectores para reforzar su poder político. En este sentido, la amenaza de la expulsión permite organizar y ordenar la presencia de migrantes irregulares en función de los intereses del Estado que sigue su propia lógica territorial del poder.

Por otro lado, la amenaza de la deportación que gestiona el poder político opera de forma involuntaria como un mecanismo de sujeción a favor de la lógica del poder capitalista, pues los riesgos que supone para el migrante visibilizar su situación dificultan la denuncia de la sobreexplotación laboral, la reivindicación de una mejora de las condiciones de trabajo, etc. No obstante, este funcionamiento acompasado de los intereses del poder político y del poder económico no se produce siempre y en todo momento. En un mercado de trabajo fuertemente regulado y sin un sector significativo de economía sumergida la definición legal y política de la irregularidad no trae como consecuencia la sobreexplotación que ha experimentado el migrante no autorizado en las últimas décadas. A modo de ilustración se puede tomar en consideración la distancia que separa la posición de los trabajadores migrantes no autorizados en las décadas de los años cincuenta y sesenta de su situación actual. A diferencia del migrante "espontáneo" de los países mediterráneos que llegaba al norte de Europa como trabajador para la industria y que en un breve lapso de tiempo era asimilado al status del trabajador migrante regular (aunque fuese bajo el régimen de trabajador invitado), los migrantes irregulares en España no se encuentran hoy en día con un régimen fordista donde son incorporados por su cualidad de trabajadores, sino con un mercado de trabajo desregulado donde son requeridos precisamente por la facilidad con la que pueden ser modelados como un suministro de mano de obra barata y "de usar y tirar" (ver también Schierup et al., 2006: 105). Mientras en el primer caso el objetivo consistía en el reclutamiento de trabajadores y se realizaban esfuerzos para regularizar su situación e incorporar a los migrantes al mercado de trabajo, reduciendo la irregularidad a una condición temporal, en el segundo caso se reproduce la irregularidad porque se contrata a los trabajadores migrantes irregulares precisamente por el hecho de encontrarse en una posición precaria. En este contexto, las tendencias neoliberales en el ámbito de la contratación intervienen en la definición de la irregularidad migratoria ampliando los contenidos específicos que son asociados desde las instituciones del Estado, pues está en sus manos determinar que el migrante sea incorporado como una figura sin ninguno de los atributos y protecciones que se atribuyen a un trabajador. La inclusión subordinada del migrante irregular en el ámbito laboral, como consecuencia, incrementa la distancia que separa la condición del migrante regular del irregular.

El resultado de estas operaciones es que las medidas que inicia el Estado en la irregularización de migraciones -tanto la definición de status legal débil y con escasos derechos, como la privación casi total de la posibilidad de ejercer acciones colectivas y de carácter político mediante el recurso de la deportabilidad-desencadenan un proceso que favorece la mercantilización de la mano de obra de los trabajadores migrantes, pero que sólo tiene lugar cuando se combina con un mercado de trabajo marcado por las tendencias de la era neoliberal. Se produce, así, deliberadamente un ámbito que no está sometido a las reglas de "paz, propiedad e igualdad" que priman en otros ámbitos y al que puede recurrir el capital para obtener mayor rentabilidad. Únicamente cuando este segundo proceso se produce, es decir cuando se combinan el funcionamiento de la lógica excluyente del Estado y la lógica expansiva de la economía capitalista en la producción de irregularidad migratoria, se puede hablar de acumulación por desposesión. 


\section{LA PRODUCCIÓN DE IRREGULARIDAD COMO MECANISMO DE ACUMULACIÓN POR DESPOSESIÓN: EL CASO ESPAÑOL}

Las diferentes leyes y medidas políticas en materia de inmigración que se han aprobado a partir de 1985 en el Estado español han afectado de forma notable a las condiciones de vida y trabajo de los migrantes categorizados como irregulares dentro de su territorio. Las restricciones introducidas por la primera legislación de extranjería, la LO 7/1985, no fueron menores y definieron de forma clara la distancia existente entre el status de turista, el status de extranjero con permiso de residencia y el status de aquéllos que no lo poseían. Además de establecer los puntos por los que debería realizarse la entrada en el territorio del Estado (art. 11), se fijó un límite a la estancia en régimen turista (art. 13). Por otro lado, la ley determinó que era requisito imprescindible para los extranjeros contar con un permiso de trabajo para poder desempeñar actividades laborales (art. 15). El efecto de la ley fue que la mayor parte de los migrantes ya presentes en España y que no procedian de la CE pasaron a ser irregulares y que se ilegalizaron las formas de trabajo que hasta el momento habían desempeñado (Calavita y Suárez-Navaz, 2003: 114; Jabardo, 1995: 86). La producción de irregularidad continuó con la introducción a partir de los años noventa del visado como un nuevo requisito para la entrada regular de los nacionales procedentes de determinados países, como Marruecos, República Dominicana o Perú (Mandria et al., 1996: 254).

Conviene precisar que no toda ley en materia de inmigración empeora necesariamente el status del trabajador migrante irregular, pues sus disposiciones podrían contemplar una reducción de los efectos y sanciones asociados a la residencia o trabajo sin autorización. Sin embargo, son escasos los esfuerzos que se han desarrollado en esta línea hasta el momento en España. Así, pese a que la segunda ley española de extranjería, la ley $4 / 2000$, que ha sido calificada mayoritariamente como una ley progresista que reconocía un amplio conjunto de derechos y medidas de integración para la población migrante, no ha entrado en vigor sin haber sido antes reformada por la ley $8 / 2000$, lo que ha truncado las expectativas de reducción de irregularidad. En cualquier caso, aquélla ya establecía la creación de los Centros de Internamiento de Extranjeros, dispositivos donde cabe privar de libertad a los extranjeros en situación administrativa irregular, no como resultado de una sanción penal ni administrativa, sino como medida para garantizar la expulsión ${ }^{6}$ (arts. 56 y 58). La ampliación del período durante el cual los migrantes pueden ser internados en este tipo de centros de cuarenta a un máximo de sesenta días ha sido una de las medidas introducidas por la última ley de extranjeria que ha profundizado aún más la precarización de la situación legal del migrante irregular?

La condición de irregularidad también ha sido afectada por intentos, finalmente fallidos, de reducción del ejercicio de derechos que preveía la ley 8/2000 para migrantes irregulares, pues se ampliaba la diferencia ya existente entre quienes poseían un status regular y quienes no. En su texto se reconocía a los extranjeros en situación administrativa irregular los derechos de huelga, sindicación, negociación colectiva, asociación y reunión, pero reservaba el ejercicio de los mismos a quienes residiesen legalmente en el territorio español. Esta limitación encubierta de derechos ha sido posteriormente declarada inconstitucional por el Tribunal Constitucional ${ }^{8}$ y ha sido enmendada en la reforma de la ley del año 2009 de manera que en este punto concreto la producción de irregularidad ha sido disuelta al menos en el nivel del reconocimiento formal.

Otra serie de medidas legales que han contribuido a dotar de significado propio a la irregularidad ha consistido en incrementar de forma progresiva, con cada nueva ley de extranjería, las sanciones impuestas a los delitos asociados a la migración irregular ${ }^{9}$, así como la vulnerabilidad del migrante frente a las instituciones. Esto último se ha conseguido mediante la introducción de medidas que contemplan el acceso de la policía a los datos del padrón de la población extranjera ${ }^{10}$, cuando éste conforma la fuente de acceso a servicios básicos como la educación o la emisión de la tarjeta sanitaria y también constituye un registro para acreditar el período de residencia en España de cara a un proceso de regularización.

Se puede tomar en consideración, asimismo, que el contenido de la irregularidad migratoria se ha modulado desde las instituciones a través del recurso a la regularización extraordinaria y la regularización por arraigo como formas de acceso más frecuentes a un status regular en España. En este segundo caso, el endurecimiento de los requisitos necesarios para poder optar a la regularización exigiendo, por ejemplo, demostrar el crecimiento de la actividad de la empresa que proporciona al migrante una oferta de trabajo, han transformado e incrementado la distancia que 
separa al status del migrante regular e irregular y en este sentido, se puede argumentar que se trata de medidas que también contribuyen a la producción de irregularidad.

El hecho de que todas estas medidas legales en materia de extranjería afecten sólo a los nacionales procedentes de países extracomunitarios y que hayan quedado excluidos los ciudadanos de la Unión Europea también ha incidido en la forma en la que se ha definido la irregularidad en el caso español, asociando la irregularidad sólo a la población extranjera procedente de ciertos Estados.

Este conjunto de medidas políticas y legales no han sido las únicas que han intervenido en la configuración de la condición del migrante irregular en España. El proceso de irregularización orquestado por las instituciones del Estado se ha entrelazado con un contexto económico particular. La existencia de una demanda importante de mano de obra no cualificada para el sector servicios y un gran número de actividades económicas que se caracterizan por la temporalidad, como la agricultura intensiva, la construcción o el turismo, han favorecido la incorporación del trabajador migrante irregular en un mercado que está escasamente regulado incluso para la mano de obra nacional (López Sala, 2006: 89). Precisamente el hecho de que el trabajo migrante haya sido devaluado hasta ser convertido en una mera mercancía gracias a la actuación combinada, aunque no concertada, del Estado y la economía capitalista permite interpretar este particular proceso de irregularización como una de las nuevas formas de acumulación por desposesión.

Las conclusiones de las investigaciones realizadas por Jabardo en las que ha analizado cómo el desarrollo del sector de la agricultura intensiva en Cataluña se encuentra vinculado al fenómeno de la migración irregular permiten indagar en esta línea de trabajo. La autora ha apuntado que la incorporación de los migrantes irregulares en el proceso productivo se ha llevado a cabo a través de la supresión de su condición de trabajadores. En los años ochenta las pequeñas explotaciones no podian contratar trabajadores nacionales porque los salarios requeridos eran inasumibles. "[S]ólo en el caso de que el trabajo no se valorara como tal trabajo, y a la vez no supusiera un input importante de capital, se podía abordar el empleo puntual de un trabajador" (Jabardo, 1995: 85). En este período en el que fue aprobado la primera ley de extranjería la presencia de migrantes irregulares con bajos salarios, con la capacidad de ser desechables y dispuestos a asumir ínfimas condiciones laborales posibilitó que todo tipo de explotaciones agrícolas pudiesen afrontar los gastos que suponía la modernización de los sistemas de producción. Según esta investigadora la asunción de estas condiciones precarias por parte del migrante se debía a que era la única forma de acceso a un empleo y la única forma de poder regularizar su status en el futuro (Jabardo, 1995: 88). En esta misma línea, el análisis que Calavita elabora sobre el empleo de migrantes irregulares en los invernadores de El Ejido subraya que éstos han posibilitado el desarrollo de una agricultura propia de una economía tardocapitalista o postfordista. Dado que la demanda de productos no es constante en los mercados, el sector se enfrenta a ella con la introducción de tecnologías en los sistemas que controlan la maduración en los invernaderos y con la contratación sólo en momentos puntuales de trabajadores para las tareas que corresponda. Los migrantes irregulares constituyen para la agricultura intensiva "una fuerza de trabajo suplementaria, cuya temporalidad es una parte integrante de este sistema de producción" (Calavita, 2005: 71) y permite la reducción de costes para hacer competitivo el producto dentro y fuera de las fronteras.

En este contexto, la condición del migrante irregular como trabajador sin derechos laborales y desechable permite conformar en el régimen de acumulación propio de la etapa del neoliberalismo un segmento en el mercado laboral altamente precarizado que, aún con elevadas tasas de paro entre los nacionales, es ocupado por migrantes y que es imprescindible para el desarrollo económico de los Estados más avanzados (Brandariz García, 2009: 2). Las ventajas que ofrece su contratación no residen únicamente en que permite disponer del trabajo migrante irregular como un suministro de mano de obra barato y sobreexplotable, sino que lo haga sólo en las fases en las que sea requerido y en unas condiciones inferiores a aquéllas que estaría dispuesto a asumir el trabajador nacional.

La tesis de Martínez Veiga en su estudio acerca de la situación de los trabajadores migrantes en las explotaciones agricolas de El Ejido es que a través de la rotación se consigue transformar el trabajo que es necesario para la economía de la zona en un trabajo contingente, redundante 0 accidental y esto a su vez repercute en la capacidad de negociación del trabajador migrante. El hecho de que la relación laboral sea muy corta y de que los puestos puedan 
ser desempeñados por cualquier trabajador de la zona "da la impresión de que todos los trabajadores son sustituibles por otros y que, por lo tanto, el trabajo en su conjunto también es sustituible, innecesario o menos necesario de lo que realmente es" (Martínez Veiga, 2004: 128). Aunque los trabajadores migrantes sean necesarios para el proceso productivo en el conjunto de El Ejido y aunque trabajen por un período largo que implicaría que fuesen considerados como trabajadores fijos, "cada uno de los trabajadores se presenta a su vez como absolutamente irrelevante puesto que siempre va a ser sustituido por otro, por otro y por otro" (Martínez Veiga, 2004: 129).

A pesar de que la agricultura sea uno de los sectores en los que la incorporación del trabajador migrante irregular ha sido clave para su desarrollo intensivo, también ha desempeñado un papel fundamental en otros sectores, por ejemplo, en la emergencia del servicio doméstico. Los datos de los procesos de regularización apuntan que los migrantes irregulares son igualmente empleados en la construcción y el turismo (para los datos del proceso de regularización de 1991, Izquierdo, 1996: 197; para los datos del proceso de regularización del año 2000, Calavita, 2005: 68). En estos casos la desregulación de la economía, que se ha conjugado con la escasa regulación previa del mercado laboral en España (Schierup et al., 2006: 106), ha generado que la contratación de trabajadores irregulares haya proliferado en diferentes sectores. Según Izquierdo, han aparecido migrantes irregulares en tareas que previamente asumian las empresas y que tras la crisis "son subcontratadas y sacadas de la actividad asalariada estable y reglada: carteros, recaderos y ordenanzas, agentes de venta, conserjes y porteros, conductores, operadores de carga y descarga, fontaneros, electricistas, montadores e informáticos" (Izquierdo, 1996: 196, énfasis en el original). En todos estos ámbitos la producción de irregularidad pone a disposición del capital una fuente de mano de obra superflua, prescindible y fácilmente reemplazable. Se trata de la fuerza de trabajo permanente de los empleados temporalmente (Beltrán, 2009: 614). Desde esta perspectiva lo que otorga valor al trabajo migrante irregular es precisamente el hecho de que la amenaza de detención y la deportabilidad lo haya convertido en una mercancía prescindible e intercambiable y que, además, la abundancia e infinitud de este tipo de trabajo no permanente le haya otorgado la característica de ser un sector permanente. Los adjetivos "superfluo" y "prescindible" se pueden emplear para dar cuenta del trabajo migrante irre- gular definido como un proceso cíclico y sin fin, marcado por la indistinción e intercambiabilidad. La mercantilización de este nuevo ámbito para la acumulación capitalista, pero que no se obtiene directamente a través de la producción, sino mediante la actuación del Estado que inicia el proceso de irregularización de determinada población extranjera permite, en definitiva, clasificar este proceso como un mecanismo más de acumulación por desposesión.

Las implicaciones que conlleva la interpretación de la producción de irregularidad migratoria en el caso español como un mecanismo de acumulación por desposesión son varias. Por un lado, plantea si la amenaza de la detención y la deportabilidad como instrumento mediante el cual se reduce notablemente la capacidad de acción política migrante caben ser interpretadas como un nuevo dispositivo de cercamiento de comunes, en la medida en la que se desprovee al migrante de la posibilidad de negociar con las instituciones y con los contratistas las condiciones en las cuales realizará su trabajo. En este sentido, la amenaza de la expulsión que caracteriza la condición de la irregularidad pone sobre la mesa que existen nuevas formas mediante las cuales se obtiene la separación del trabajador de sus medios de producción y que éstos no tienen por qué ser necesariamente materiales. Por otro lado, la irregularización, comprendida como un dispositivo de acumulación a través de desposesión, pone sobre la mesa que el papel que desempeña la esfera económica en la producción de irregularidad no es derivado de la actuación del Estado, ni viceversa. De esta manera apunta a las relaciones dialécticas que se establecen entre estos dos ámbitos y aporta una nueva perspectiva con la que abordar el estudio de la producción de irregularidad.

\section{A MODO DE CONCLUSIÓN}

A lo largo de este trabajo se ha prestado atención al debate que ha subrayado la necesidad de explicitar los procesos que intervienen en la configuración de la condición del migrante irregular. Tratando de superar los acercamientos unidimensionales en los que el proceso de irregularización de las migraciones se explica o bien como un efecto de la ley o bien como un resultado de la lógica de explotación que impone la economía capitalista, se ha propuesto una aproximación en la que estos dos polos mantienen una relación dialéctica. 
A partir del análisis del proceso concreto de irregularización de las migraciones de países extracomunitarios que ha tenido lugar en España, se ha identificado que la subordinación de la posición del migrante en este contexto se ha llevado a cabo mediante la combinación de un status legal débil, la reducción de la agencia política migrante a través de la amenaza de la detención y la expulsión y su incorporación en el mercado laboral no como trabajador, sino como una mera mercancía. La conjugación de estos procesos, que responden a dinámicas independientes, aunque puedan estar ocasionalmente vinculadas, ha conducido a la apertura de un nuevo ámbito para la mercantilización que ha afectado a la fuerza de trabajo migrante irregular desprovista de la mayor parte de las barreras a la explotación que se ofrecen a trabajadores nacionales y migrantes con status regular. Las características conforme a las cuales se ha desarrollado este proceso permiten calificar a la producción de irregularidad migratoria que ha tenido lugar en España como un mecanismo de acumulación por desposesión.

\section{NOTAS}

1 Una excepción notable es el caso del filósofo Gabriel Bello, quien en su trabajo Emigración y ética (2011) ha apostado por la nomenclatura "migrante irregular(izado)" para marcar la dimensión de la producción.

2 En la actualidad esta perspectiva se puede identificar también en el trabajo de Brandariz (2009), pues sostiene explícitamente que en la gestión de las migraciones la ley es un instrumento que actúa al compás de los intereses del capital. Blanca Garcés Mascareñas (2010) ha planteado que las investigaciones de Kitty Calavita se han desarrollado también según esta perspectiva, pero me distanciaré de esta afirmación, pues considero que su trabajo presenta un enfoque más complejo que los anteriores. Para Calavita el papel de la ley se entrelaza con el del mercado de trabajo en la producción de irregularidad, pero no necesariamente como un efecto de aquélla. La marginalidad legal y económica se constituyen mutuamente en su planteamiento, pero ello no implica que pueda reducirse el papel de la ley al del capitalismo (Calavita, 2005: 72).

Recibido: 27 de noviembre de 2011 Aceptado: 21 de diciembre de 2011
3 El punto de vista que se defiende en este trabajo es que la condición del migrante irregular no se puede reducir a una cuestión de privación de derechos. Se considera que el rasgo definitorio del status irregular es que el migrante dificilmente puede contestar a las intervenciones del Estado para reducir su status legal o al tratamiento que recibe por parte de la administración. La privación es, por tanto, más profunda. Se trata de una condición de extrema vulnerabilidad y carencia de poder en la que privación de agencia política y la subordinación social no son cuestiones secundarias.

4 Si las instituciones decidiesen ignorar la presencia de migrantes sin autorización de entrada o residencia o si decidiesen aligerar los trámites de adquisición de permiso de residencia y trabajo reduciendo la irregularidad a una situación que se resuelve con un simple trámite administrativo se podría cuestionar que la categoria "migrante irregular" tenga una especificidad propia en relación con la del migrante regular. Tal sería el caso de la gestión de las migraciones del sur de Europa en Francia durante las décadas de los años cincuenta y sesenta. A pesar de que la migración no autorizada era considerada delito desde la aprobación de la ordenanza 45-2658, de 2 de noviembre de 1945 relative aux conditions d'entrée 
et de séjour en France des étrangers et portant création de l'Office national d'immigration, ésta no vino acompañada de la aplicación de las penas previstas. Además, a partir de 1956 se puso en marcha un procedimiento mediante el cual se pudo regularizar la situación de los trabajadores extranjeros que no habían entrado por los cauces establecidos por la ley.

5 Esta cita ha sido modificada ligeramente con respecto a la traducción de Juan Mari Madariaga en la edición de Akal (2007) siguiendo el texto original de Harvey en The New Imperialism.

6 Desde el ámbito académico se ha cuestionado que éste constituya su objetivo en la práctica porque las estimaciones realizadas sobre el número de expulsiones ejecutadas en relación con los internamientos se sitúan en torno al 18 ó 25\% (Brandariz García, 2009: 2).

7 Uno de los motivos que han justificado la aprobación de la ley 2/2009 ha sido la adopción de diferentes normativas comunitarias, entre ellas la Directiva 2008/115/CEE, que afectaba los procedimientos de retorno de los nacionales de terceros países en situación de estancia irregular. A pesar de que el plazo máximo que fijaba dicha directiva para el internamiento de migrantes en situación irregular era de dieciocho meses y no afectaba el plazo establecido en la normativa española, este marco se aprovechó para incrementar el plazo de internamiento de cuarenta a sesenta días.

8 Sentencias del Tribunal Constitucional 236/2007, de 7 de noviembre, y 259/2007 de 19 de diciembre.

9 Así, la Ley Orgánica 2/2009 ha introducido en el Título III nuevas infracciones con el objetivo de evitar "matrimonios de conveniencia, la promoción de la inmigración irregular por medios indirectos o el falseamiento de datos para el empadronamiento" y ha incrementado las sanciones para todas las infracciones.

10 Estas medidas han sido introducidas en el texto de la Ley Orgánica 14/2003 de Reforma de la Ley Orgánica 4/2000.

\section{BIBLIOGRAFÍA}

Abraham, I. y Van Schendel, W. (2005): "The Making of Illicitness", en Illicit Flows and Criminal Things: States, Borders, and the Other Side of Globalization, Bloomington e Indianapolis, Indiana U.P., 1-37.

Amin, S. (1974): La acumulación a escala mundial, Madrid, Siglo XXI.

Arendt, H. (2006): Los orígenes del totalitarismo, Madrid, Alianza.

Ashman, S. y Callinicos, A. (2006): "Capital Accumulation and the State System: Assessing David Harvey's The New Imperialism", Historical Materialism, 14 (4), 107-131.

Auerbach, N. y Negi, R. (2009): "Primitive Accumulation, Capitalism and Development", Human Geography, 2 (3), 100-103.

Bach, R. L. (1978): "Mexican Immigration and the American State", International Migration Review, 12 (4), 536558.

Beltrán, C. (2009): "Going Public: Hannah Arendt, Immigrant Action, and the Space of Appearance", Political Theory, 37 (5), 595-622.

Bello Reguera, G. (2011): Emigración y ética: humanizar y deshumanizar, Madrid, Plaza y Valdés.

Bonefeld, W. (2001): "The Permanence of Primitive Accumulation: Commodity Fetishism and Social Constitution",
The Commoner, 2, 1-15, http://www. commoner.org.uk.

Brandariz García, J. A. (2009): "Funcionalidad de la construcción de los migrantes como sujetos de riesgo en el sistema penal español", Jura Gentium, 1, 1-10.

Brenner, R. (2006): "What Is, and What Is Not, Imperialism?", Historical Materialism, 14 (4), 79-105.

Brüscher, B. (2009): "Letters of Gold: Enabling Primitive Accumulation Through Neoliberal Conservation", Human Geography, 2 (3), 91-94.

Burawoy, M. (1976): "The Functions and Reproduction of Migrant Labor", The American Journal of Sociology, 81 (5), 1050-1087.

Calavita, K. (1998): "Immigration, Law, and Marginalization in a Global Economy: Notes from Spain", Law \& Society Review, 32 (3), 529-566.

Calavita, K. (2005): Immigrants at the Margins, Nueva York, Cambridge U.P.

Calavita, K. y Suárez-Navaz, L. (2003): "Spanish Immigration Law and the Constructions of Difference", en Perry, R. W./Maurer, B. (eds.), Gobalization under Construction, Minneapolis y Londres, University of Minnesota Press, 99-127.

Clandestino Research Project (2009): "Pathways Into Irregularity: The Social Construction of Irregular Migration", HWWI, European Commission, http:// irregular-migration.hwwi.de/.

Coutin, S. (2000): Legalizing Moves: Salvadoran Inmigrants' Struggle for U.S. Residency, Ann Arbor, The University of Michigan Press.

Dalla Costa, M. (2005): "Development and Reproduction", The Commoner, 10, 172199, http://www.thecommoner.org.uk.

Dauvergne, C. (2008): Making People Illegal, Nueva York, Cambridge U.P.

De Angelis, M. (2004): "Separating the Doing and the Deed: Capital and the 
Continuous Character of Enclosures", Historical Materialism, 12 (2), 57-87.

De Genova, N. (2002): "Migrant 'Illegality' and Deportability in Everyday Life", Annual Review of Anthropology, 31, 419-447.

Düvell, F. (2010): "Irregular Migration: A global, Historical and Economic Perspective", en Vertovec, S. (ed.), Migration, Abingdon, Routledge, 289-310.

Garcés-Mascareñas, B. (2010): "Legal Production of Illegality in a Comparative Perspective. The Cases of Malaysia and Spain", Asia Europe Journal, 8 (1), 77-89.

Glassman, J. (2006): "Primitive Accumulation, Accumulation by Dispossession, Accumulation by 'Extra-economic' Means", Progress in Human Geography, 30 (5), 608-625.

Goldring, L.; Berinstein, C. y Bernhard, J. (2007): "Institutionalizing Precarious Immigration Status in Canada", Early Childhood Education Publications and Research, Paper 4, http://digitalcommons.ryerson.ca/ece/4.

Hartsock, N. (2006): "Globalization and Primitive Accumulation: The Contributions of David Harvey's Dialectical Marxism", en Castree, N.; Gregory, D. (eds.), David Harvey: A Critical Reader, Malden, Oxford y Victoria, Blackwell, 167-190.

Harvey, D. (1998): La condición de la postmodernidad: Investigación sobre los orígenes del cambio cultural, Buenos Aires, Amorrortu.

Harvey, D. (2007a): El Nuevo Imperialismo, Madrid, Akal.

Harvey, D. (2007b): Breve Historia del Neoliberalismo, Madrid, Akal.

Izquierdo, A. (1996): La inmigración inesperada, Madrid, Trotta.

Jabardo, M. (1995): "Etnicidad y mercado de trabajo: Inmigración africana en la agricultura catalana", Perspectiva social, 36, 81-95.

King, R. (2001): "The Troubled Passage: Migration and Cultural Encounters in Southern Europe", en The Mediterranean Passage: Migration and New Cultural Encounters in Southern Europe, Liverpool, Liverpool U.P.

López Sala, A. M. (2003): "La inmigración irregular en la investigación sociológica", en Godenau, D.; Zapata Hernández, V. M. (eds.), La inmigración irregular, una aproximación interdisciplinar, Tenerife, Cabildo Insular de Tenerife, 161-183.

Luxemburgo, R. (1951): The Accumulation of Capital, Londres, Routledge and Kegan Paul Ltd.

Mahmud, T. (2010): "'Surplus Humanity' and Margins of Legality: Slums, Slumdogs, and Accumulation by Dispossession", Seattle University School of Law Research Paper, 14 (10-26), 1-82, http:// ssrn.com/abstract $=1678202$.

Martínez Veiga, U. (2004): Trabajadores invisibles. Precariedad, rotación y pobreza de la inmigración en España, Madrid, Catarata.

Marx, K. (2009): El Capital: Crítica de la economía política, tomo I, vol. 3, Madrid, Siglo XXI.

Midnight Notes Collective (2001): "New Enclosures", The Commoner, 2, 1-15, http://www.thecommoner.org.uk.

Nevins, J. (2002): Operation Gatekeeper: The Rise of the "Illegal Alien" and the Making of the U.S.-Mexico Boundary, New York, London, Routledge.

Ngai, M. (2004): Impossible Subjects, Princeton, Princeton U.P.

Perelman, M. (2000): The Invention of Capitalism. Classical Political Economy and the Secret History of Primitive Accumulation, Durham y Londres, Duke U.P.
Proudham, S. (2007): "The Fictions of Autonomous Invention: Accumulation by Dispossession, Commodification and Life Patents in Canada", Antipode, 39 (3), 406-429.

Retort (2005): Afflicted Powers: Capital and Spectacle in a New Age of War, Londres, Verso.

Romero, E. (2010): Un deseo apasionado de trabajo más servicial y barato. Migraciones, fronteras y capitalismo, Oviedo, Cambalache.

Schierup, C.-U.; Hansen, P. y Castles, S. (2006): Migration, Citizenship, and the European Welfare State: A European Dilemma, Oxford, Oxford U.P.

Solanes Corella, Á. (2003): "La irregularidad que "genera" la ley de extranjería", Revista de derecho migratorio y extranjería, 4, 125-139.

Vasudevan, A.; McFarlane, C. y Jeffrey, A. (2008): "Spaces of enclosure", Geoforum, 39 (5), 1641-1646.

Veriava, A. (2007): "Unlocking the Present? Two Theories of Primitive Accumulation", en Bond, P.; Chitonge, $\mathrm{H}_{\text {.; }}$ Hopfmann, A. (eds.), The Accumulation of Capital in Southern Africa. Rosa Luxemburg's Contemporary Relevance, Johannesburgo, Rosa Luxemburg Foundation, 46-62.

Wolpe, H. (1972): "Capitalism and cheap labour-power in South Africa: from segregation to apartheid", Economy and Society, 1 (4), 425.

Wood, E. M. (2006): "Logics of Power: A Conversation with David Harvey", Historical Materialism, 14 (4), 9-34.

Zarembka, P. (2002): "Primitive Accumulation in Marxism, Historical or Transhistorical Separation from means of Production?", The Commoner, Special Issue 2002, 1-9, http://www. commoner.org.uk. 